\title{
Update on gastroesophageal reflux and respiratory disease in children
}

\author{
Susan R Orenstein MD
}

\begin{abstract}
SR Orenstein. Update on gastroesophageal reflux and respiratory disease in children. Can J Gastroenterol 2000;14(2):131135. Pediatric respiratory diseases have been linked to gastroesophageal reflux disease (GERD), but evidence regarding the association and its potential mechanisms continues to accumulate, and important aspects remain to be determined. Evidence for the association in two common pediatric respiratory disorders - infantile apnea and asthma in older children - and difficult clinical issues associated with the diagnosis and treatment of these two disorders are reviewed. The provocative embryological and physiological connections between the upper gastrointestinal tract and the respiratory tract, and recent understanding of the compensatory anatomy and physiology that protect the normal individual from respiratory manifestations of GERD are also explored. Dysfunctions of these protections likely underlie the pathophysiology of these disorders.
\end{abstract}

Key Words: Gastroesophageal reflux disease; Respiratory disease

\section{Le point sur le reflux gastro-œsophagien et la maladie respiratoire chez l'enfant}

RÉSUMÉ : Les maladies respiratoires infantiles ont été associées au reflux gastro-œsophagien (RGO), mais les preuves de ce lien et de ses mécanismes potentiels continuent de s'accumuler et d'importants aspects restent à élucider. On passe ici en revue les preuves de ce lien dans deux maladies respiratoires infantiles répandues, soit l'apnée et l'asthme infantiles, et les enjeux cliniques que posent le diagnostic et le traitement de ces deux maladies. On aborde en outre les connexions embryologiques et physiologique controversées entre le tractus digestif supérieur et les voies respiratoires et les récentes observations relatives à l'anatomie et à la physiologie compensatoires mises en place pour protéger l'individu normal des manifestations respiratoires du RGO. Une dysfonction de ces mécanismes protecteurs sous-tend probablement la physiopathologie des ces maladies.
$\mathrm{P}$ ediatric respiratory diseases have been linked to gastroesophageal reflux disease (GERD) for some time, but evidence regarding the association and its potential mechanisms continues to accumulate, and important aspects remain to be determined. The present review of this association explores the evidence for the association in two common pediatric respiratory disorders - infantile apnea and asthma in older children. The evidence for the associations is explored, and the difficult clinical issues associated with the diagnosis and treatment of these two disorders are identified. The provocative embryological and physiological connections between the upper gastrointestinal tract and the respiratory tract, and recent understanding of the compensatory anatomy and physiology that protect the normal individual from respiratory manifestations of GERD are explored. Dysfunctions of these protections likely underlie the pathophysiology of these disorders.

\section{EVIDENCE FOR THE ASSOCIATION BETWEEN GERD AND RESPIRATORY DISEASES}

The evidence linking respiratory diseases with GERD has been accumulating for about three decades. In increasing order of rigour, this evidence may be characterized as epidemiological, temporal, therapeutic and experimental. Epidemio-

This Mini-review was prepared from a presentation made at the 1998 Word Congress of Gastroenterology, September 6 to 11, 1998, Vienna, Austria

Division of Pediatric Gastroenterology, University of Pittsburgh School of Medicine and Children's Hospital of Pittsburgh, Pittsburgh, Pennsylvania, USA

Correspondence and reprints: Dr SR Orenstein, Division of Pediatric Gastroenterology, Children's Hospital of Pittsburgh, 3705 Fifth Avenue at

DeSoto Street, Pittsburgh, Pennsylvania 15213, USA. Telephone 412-692-5180, fax 412-692-7355, e-mail orensts@chplink.chp.edu

Received for publication Jan 21, 1999. Accepted January 28, 1999 
logical studies have usually provided the first evidence linking the disorders, by showing that children with a particular type of respiratory disease have an increased incidence of GERD. This type of association indicates no causality, however. The second type of study shows a temporal relationship between spontaneous episodes of acid reflux and an intermittent respiratory symptom, usually by using an esophageal $\mathrm{pH}$ probe to detect acid reflux episodes; these studies are limited in the type of respiratory symptom or disease they can evaluate and are unable to detect effects of neutral $\mathrm{pH}$ refluxate, such as those that occur 1 to $2 \mathrm{~h}$ after feeding milk formula to an infant. However, they do indicate a closer association than that indicated by the epidemiological studies. The third type of study treats the GERD and watches for improvement in the respiratory disease. This type of study provides a clearer indication of causality and direction of causality than does the epidemiological or temporal association study. However, many of these studies initially suffered from the limitations on therapeutic modalities available for GERD and, therefore, provided negative results. In addition, the natural tendency of GERD and apnea, for example, to resolve during infancy makes beneficial effects attributable to the therapy itself somewhat ambiguous. The final type of study, experimental induction of respiratory symptoms by provoking or mimicking reflux, is the most rigorous and the most difficult to do, particularly in young children, both for practical and for ethical reasons. These studies have provided the clearest indication that reflux causes a particular symptom.

Apnea: Nearly 30 years ago, the widening availability of $\mathrm{pH}$ probe technology made it possible to identify infants with increased reflux, even when it was not overtly regurgitated. This technology permitted investigators to recognize that many babies with cyanotic apneic episodes had an increased amount of acid reflux (1-4). The most extensive such study evaluated about 1400 infants with apnea and found excessive reflux in about half of them (5).

Studies showing a temporal relationship between reflux documented by $\mathrm{pH}$ probe (or by observed regurgitation) and apnea or hypoxemia documented by polysomnography bolstered the epidemiological data $(2,6,7)$, but a number of negative studies called the association into question (8-11). Examination of these studies shows their limitations - no apneas detected during $\mathrm{pH}$ probe study (some because techniques were not used to identify obstructive apnea occurring during continuing chest wall movement) and no reflux detected because of frequent milk feedings. Apnea is a response of infants to a number of stimuli, and the negative studies cannot prove that reflux is not one possible stimulus.

Several therapeutic studies reported resolution of recurrent apnea following fundoplication (14 babies), pharmacotherapy for reflux (13 babies) and even conservative measures (10 babies) (12-14). The natural history of infantile apnea to resolve in most cases warrants caution in interpreting these studies. Further support for fundoplication's efficacy (with a GERD pharmacotherapy 'control group') was subsequent death from apnea occurring in none of 88 fundoplicated infants at high risk for apnea but in three of 44 medically treated ones (15).

Experimental studies indicated that intraluminal esophageal acidification could induce apnea in some susceptible infants $(14,16,17)$.

The characteristics of apnea that are more likely to be due to GERD, improving clinical selection of the infants most likely to improve with antireflux therapy, are apnea occurring while the infant is awake, supine or seated, and apnea occurring within approximately $1 \mathrm{~h}$ after feeding (2). The apnea is usually obstructive, identifiable by apparently ineffectual respiratory efforts. Thus, the baby becomes stiff and turns red and struggles initially with the respiratory efforts. Milk may be visible at the mouth or nose.

Difficult issues in reflux-associated infantile apnea are determining which babies need formal investigation, which would benefit from home monitoring, which (if any) should have fundoplication and when safely to discontinue antireflux therapy and home monitoring. Many babies presenting with a very characteristic history respond to conservative measures. Although pharmacotherapy is often used, the additional benefit conferred is unknown. Supine or seated positioning is such a profound provocation for this type of event that proscribing it probably confers the most therapeutic benefit short of fundoplication. Thickening of feedings (to a caloric density of 30 calories/ounce) allows smaller volume feedings to be given and minimizes regurgitation, so is likely to provide additional benefit. Pharmacotherapy usually incorporates both a prokinetic agent and acid suppression with an $\mathrm{H}_{2}$ blocker, although the latter may not be very relevant for postprandial apnea, which occurs when the infant's gastric contents are usually neutral.

Asthma: Studies in pediatric asthma paralleled those in apnea, gradually providing increasing evidence for a role of GERD in provoking or exacerbating asthma. Many epidemiological studies have shown a prevalence of GERD in asthma to be as much as $50 \%$ or more (18). More reflux disease was detected in children with nocturnal exacerbations of asthma and with worse asthma $(19,20)$.

Temporal association of reflux with asthma symptoms or with measured bronchospasm was found in 45 children in two studies $(19,21)$.

Treatment of reflux with ranitidine (22), cisapride (18) or other pharmacotherapy improved asthma in a number of children; the improvement was more likely to occur if the child had reflux symptoms as well as asthma. Negative studies are explained by their focus on subsets of children whose asthma is not provoked by reflux or by their use of inadequate therapy (23). (The necessity of aggressive antireflux therapy, often requiring a proton pump inhibitor and months of therapy, has been shown by a number of adult studies.)

As with infantile obstructive apnea, intraluminal esophageal acidification has been shown to provoke bronchial constriction and increased airway resistance in children, as in adults, by a vagal pathway blocked by atropine $(18,23-28)$.

Children with asthma who are most likely responsive to antireflux therapy are those with reflux symptoms (heart- 
burn, regurgitation), reflux symptoms preceeding exacerbations of bronchospasm, nocturnal asthma and nonallergic asthma. (It must be remembered that chronic cough, lasting more than three weeks, is a very common presentation of asthma in children and is often associated with GERD as well.) Studies using $\mathrm{pH}$ probe evaluation have suggested that individuals with reflux episodes preceeding wheezing or cough, or with proximal esophageal acidification for more than $1.1 \%$ of the study, are most likely to respond to antireflux therapy. Any child with asthma that is difficult to manage or requires steroids should have reflux considered as a potential cause.

The characteristics of therapy that are important for children who have reflux-exacerbated asthma are maintaining optimal antiasthma therapy, using reflux therapy that is both powerful (generally including a proton pump inhibitor, but keeping in mind that most proton pump inhibitors allow nocturnal breakthrough of acid suppression) and prolonged (generally two months or longer), and focusing on nocturnal reflux.

\section{GASTROINTESTINAL-RESPIRATORY CONNECTIONS}

The 28-day human embryo, $5 \mathrm{~mm}$ in length, has a laryngotracheal groove that develops into a lung bud off of the gastrointestinal tract. This design problem, causing the pathways for air and food to intersect in the pharynx for the rest of a normal human's life, is at the root of the interactions between reflux and respiratory disease. Not only does the luminal anatomy intersect, but also neural connections and reflexes inextricably join the gastrointestinal tract to the respiratory tract.

The protective adaptations that prevent massive aspiration in most people are being clarified. Several have been well identified for decades, but others are just now being characterized.

During swallowing, the soft palate blocks the nasopharynx, and the larynx and epiglottis close off the lower respiratory tract, allowing food to enter the upper esophageal sphincter (UES), which has been opened for the purpose by the act of swallowing, and allowed to close and resume its resting tone shortly thereafter. The lower esophageal sphincter (LES) relaxes at about the same time but remains relaxed much longer, so that the peristaltic wave, travelling only at about $3 \mathrm{~cm} / \mathrm{s}$ (or more than $10 \mathrm{~s}$ to traverse a normal adolescent esophagus) does not encounter an already closed LES.

With the ingested food in the stomach, the UES and LES remain closed, providing a dual barrier for egress retrograde. The pair of sphincters are physiologically opened to allow vomiting of toxic material or belching to relieve potentially harmful intragastric pressure. Increases in gastric pressure that are simply transmitted from increases in intraabdominal pressure, due to straining, for example, do not require the same protective venting as do isolated increases in gastric pressure. Therefore, the crural diaphragm's bolstering of the LES (which, as with the LES itself, remains in force unless relaxed during gastric venting) increases during straining.

Reflux episodes, universal in normal children and adults, are likely the result of the sensitivity of pressure-relieving mechanisms; for the most part they involve relaxation of the LES but not the UES in mature humans. They produce no harm if the refluxate is rapidly cleared from the esophagus by primary or secondary peristalsis. Some reflux episodes, decreasingly common as infants grow to adulthood, allow refluxate into the esophagus with characteristics that prompt the UES to relax as well, and usually result in regurgitation. The characteristics that prompt regurgitation through the UES are undergoing evaluation but must include the relatively huge meal volume required for the infant to triple its weight in 12 months. Regurgitant reflux is also more likely than nonregurgitant reflux when LES relaxation is accompanied by abdominal wall muscular contraction (29). Regurgitant reflux occurs daily in the majority of normal infants but rarely in normal adults.

Refluxate that traverses the UES threatens the airway. Material that is refluxed into the pharynx, but not actively enough to exit the mouth, is returned to the esophagus and stomach by the pharyngeal swallow reflex, similar to an ordinary swallow (primary peristalsis) but without lingual participation. Several other newly identified reflexes serve to protect the airway from gastroesophagopharyngeal refluxate. The esophago-UES contractile reflex increases the UES pressure when pressure rises in the esophagus (personal communication, R Shaker). The pharyngo-UES contractile reflex increases the UES pressure when small volumes of water are perfused into the pharynx (30). Both of these can be conceived as mechanisms to limit egress of refluxate from the esophagus.

The esophagoglottal closure reflex, also prompted by increased esophageal pressure, provides anticipatory glottic closure in a setting when UES pressure may not hold, so that the glottis is closed if refluxate escapes the esophagus (31).

Finally, two reflex mechanisms close the glottis when it is threatened by material in the pharynx. The first is provoked by stimulation of epiglottal 'taste buds', with many of the characteristics of lingual taste buds, except that they are on the laryngeal, rather than the lingual, surface of the epiglottis (thus poorly situated for the normal sampling of nutrients) and that they respond to water (and hydrochloric acid) more strongly than to saline (32). Their characteristics make them ideal for identifying material that should be kept out of the airway. The second type of receptor to protect the glottis consists of mechanoreceptors on the aryepiglottic folds. The glottic closure is stimulated by faint puffs of air applied to this area of entry to the airway. The threshold for this response is $4 \mathrm{mmHg}$ pressure applied at a distance of $2 \mathrm{~mm}$ from the fold, and normal individuals respond reliably below $6 \mathrm{mmHg}$ pressure (33-40). The important protective role of this reflex is indicated by a report (in two adults) of dysphagia due to a brain stem stroke, which was ameliorated by microneurorrhaphy restoring the reflex (41).

It is tempting to postulate that infantile apnea, for exam- 
ple, is promoted by immaturities or developmental abnormalities in these normal reflexes (42). Abnormally sensitive or abnormally prolonged glottal closure reflexes may provoke prolonged apnea as a response to refluxate in the pharynx. Immaturities of the pharyngeal swallow may inhibit the proper movement of refluxed pharyngeal material back into the esophagus.

Lower respiratory obstruction, as occurs in asthma, may result from even more complex interactions with reflux. Not only might deficits in the laryngeal closure mechanisms enumerated above allow aspiration of refluxed gastric contents into the airway, to produce local effects, but also reflexive connections between the esophagus and airway almost certainly play a role in some instances of bronchospasm, without the need to postulate glottic defects and actual

\section{REFERENCES}

1. Ramenofsky ML, Leape LL. Continuous upper esophageal pH monitoring in infants and children with gastroesophageal reflux, pneumonia, and apneic spells. J Pediatr Surg 1981;16:374-8.

2. Spitzer AR, Boyle JT, Tuchman DN, Fox WW. Awake apnea associated with gastroesophageal reflux: a specific clinical syndrome. J Pediatr 1984;104:200-5.

3. Newman LJ, Russe J, Glassman MS, et al. Patterns of gastroesophageal reflux (GER) in patients with apparent life-threatening events. J Pediatr Gastroenterol Nutr 1989;8:157-60.

4. Veereman-Wauters G, Bochner A, Van Caillie-Bertrand M. Gastroesophageal reflux in infants with a history of near-miss sudden infant death. J Pediatr Gastroenterol Nutr 1991;12:319-23.

5. Kahn A, Rebuffat E, Franco P, N'Duwimana M, Blum D. Apparent life-threatening events and apnea of infancy. In: Beckerman R, Brouilette R, Hunt C, eds. Respiratory Control Disorders in Infants and Children. Baltimore: Williams \& Wilkins, 1992:178-89.

6. See CC, Newman LJ, Berezin S, et al. Gastroesophageal refluxinduced hypoxemia in infants with apparent life-threatening event(s). Am J Dis Child 1989;143:951-4.

7. Menon AP, Schefft GL, Thach BT. Apnea associated with regurgitation in infants. J Pediatr 1985;106:625-9.

8. MacFadyen U, Hendry G, Simpson H. Gastro-oesophageal reflux in near-miss sudden infant death syndrome or suspected recurrent aspiration. Arch Dis Child 1983;58:87-91.

9. Ariagno RL, Guilleminault C, Baldwin R, Owen BM. Movement and gastroesophageal reflux in awake term infants with 'near miss' SIDS, unrelated to apnea. J Pediatr 1982;100:894-7.

10. Sacre L, Vandenplas Y. Gastroesophageal reflux associated with respiratory abnormalities during sleep. J Pediatr Gastroenterol Nutr 1989;9:28-33.

11. Walsh JK, Farrell MK, Keenan WJ, Lucas M, Kramer M. Gastroesophageal reflux in infants: relation to apnea. J Pediatr 1981;99:197-201.

12. Leape LL, Holder TM, Franklin JD, Amoury RA, Ashcraft KW. Respiratory arrest in infants secondary to gastroesophageal reflux. Pediatrics 1977;60:924-8.

13. Newman LJ, Russe J, Glassman MS, et al. Patterns of gastroesophageal reflux (GER) in patients with apparent life-threatening events. J Pediatr Gastroenterol Nutr 1989;8:157-60.

14. Herbst JJ, Book LS, Bray PF. Gastroesophageal reflux in the 'near miss' sudden infant death syndrome. J Pediatr 1978;92:73-5

15. Jolley S, Halpern L, Tunnell W, Johnson D, Sterling C. The risk of sudden infant death from gastroesophageal reflux. J Pediatr Surg 1991;26:691-6.

16. Herbst JJ, Minton SD, Book LS. Gastroesophageal reflux causing respiratory distress and apnea in newborn infants. J Pediatr 1979;95:763-8

17. Pickens DL, Schefft G, Thach BT. Prolonged apnea associated with upper airway protective reflexes in apnea of prematurity. Am Rev Respir Dis 1988;137:113-8.

18. Tucci F, Resti M, Fontana R, Novembre E, Lami C, Vierucci A. Gastroesophageal reflux and bronchial asthma: Prevalence and effect of cisapride therapy. J Pediatr Gastroenterol Nutr 1993;17:265-70. aspiration. Airway obstruction subsequent to reflux may be caused by aspirated material, secreted mucus (in response to inflammation induced by aspiration or even reflexly stimulated as a response to reflux alone), mucosal edema (also induced by chemical mediators of inflammation or by neural pathways) and muscular spasm (bronchospasm mediated locally or reflexly) (43). Because respiratory disease may also provoke reflux in numerous ways, it is important to maintain optimal therapy aimed at the respiratory symptoms themselves, as well as at reflux.

Understanding the complexity of the interactions between the upper gastrointestinal tract and the airway may allow children with some of the greatest morbidity from respiratory disease to be more optimally managed with treatment directed at reflux as well as at the airway disease itself.

19. Martin ME, Grunstein MM, Larsen GL. The relationship of gastroesophageal reflux to nocturnal wheezing in children with asthma. Ann Allergy 1982;49:318-22.

20. Gustafsson PM, Kjellman NIM, Tibbling L. Oesophageal function and symptoms in moderate and severe asthma. Acta Paediatr Scand 1986;75:729-36

21. Gustafsson PM, Kjellman NIM, Tibbling L. Bronchial asthma and acid reflux into the distal and proximal oesophagus. Arch Dis Child 1990;65:1255-8

22. Gustafsson P, Kjellman NI, Tibbling L. A trial of ranitidine in asthmatic children and adolescents with or without pathologic gastro-oesophageal reflux. Eur Respir J 1992;5:201-6.

23. Shapiro GG, Christie DL. Gastroesophageal reflux in steroiddependent asthmatic youths. Pediatrics 1979;63:207-12.

24. Andersen L, Schmidt A, Bundgaard A. Pulmonary function and acid application in the esophagus. Chest 1986;90:358-63.

25. Davis RS, Larsen GL, Grunstein MM. Respiratory response to intraesophageal acid infusion in asthmatic children during sleep. J Allergy Clin Immunol 1983;72:393-8.

26. Mansfield L, Stein M. Gastroesophageal reflux and asthma: A possible reflex mechanism. Ann Allergy 1978;41:224-6.

27. Mansfield L, Hameister H, Spaulding H, Smith N, Glab N. The role of the vagus nerve in airway narrowing caused by intraesophageal hydrochloric acid provocation and esophageal distention. Ann Allergy 1981;47:431-4.

28. Spaulding H, Mansfield L, Stein M, Sellner J, Gremillion D. Further investigation of the association between gastroesophageal reflux and bronchoconstriction. J Allergy Clin lmmunol 1982;69:516-21.

29. Orenstein S, Dent J, Deneault L, et al. Regurgitant reflux, vs. non-regurgitant reflux, is preceded by rectus abdominis contraction in infants. Neurogastroenterol Motil 1994;6:271-7.

30. Shaker R, Ren J, Xie P, Lang I, Bardan E, Sui Z. Characterization of the pharyngo-UES contractile reflex in humans. Am J Physiol 1997;273:854-8

31. Shaker R, Ren J, Kern M, Dodds W, Hogan W, Li Q. Mechanisms of airway protection and UES opening during belching. Am J Physiol 1992;262:G621-8

32. Sant'Ambrogio MO. Laryngeal reflexes. In: Sant'Ambrogio MO, ed. Respiratory Function of the Upper Airway. New York: Marcel Dekker Inc, 1990:259-302.

33. Aviv J, Martin J, Keen M, Debell M, Blitzer A. Air pulse quantification of supraglottic and pharyngeal sensation: A new technique. Ann Otol Rhinol Laryngol 1993;102:777-80.

34. Aviv J, Martin J, Jones M, et al. Age-related changes in pharyngeal and supraglottic sensation. Ann Otol Rhinol Laryngol 1994:103:749-52

35. Aviv J, Martin J, Sacco R, et al. Supraglottic and pharyngeal sensory abnormalities in stroke patients with dysphagia. Ann Otol Rhinol Laryngol 1996;105:92-7.

36. Aviv J, Sacco R, Mohr J, et al. Laryngopharyngeal sensory testing with modified barium swallow as predictors of aspiration pneumonia after stroke. Laryngoscope 1997;107:1254-60. 
37. Aviv J. Sensory discrimination in the larynx and hypopharynx. Otolaryngol Head Neck Surg 1997;116:331-4.

38. Aviv J, Kim T, Sacco R, et al. FEESST: A new bedside endoscopic test of the motor and sensory components of swallowing. Ann Otol Rhinol Laryngol 1998;107:378-87.

39. Aviv J, Sacco R, Thomson J, et al. Silent laryngopharyngeal sensory deficits after stroke. Ann Otol Rhinol Laryngol 1997;106:87-93.

40. Aviv J, Kim T, Thomson J, Sunshine S, Kaplan S, Close L. Fiberoptic endoscopic evaluation of swallowing with sensory testing (FEESST) in healthy controls. Dysphagia 1998;13:87-92.

41. Aviv J, Mohr J, Blitzer A, Thomson JE, Close LG. Restoration of laryngopharyngeal sensation by neural anastomosis. Arch Otolaryngol Head Neck Surg 1997;123:154-60.

42. Downing SE, Lee JC. Laryngeal chemosensitivity: A possible mechanism for sudden infant death. Pediatrics 1975;55:640-9.

43. Putnam PE, Ricker DH, Orenstein SR. Gastroesophageal reflux. In: Beckerman R, Brouilette R, Hunt C, eds. Respiratory Control Disorders in Infants and Children. Baltimore: Williams \& Wilkins; 1992:322-41. 


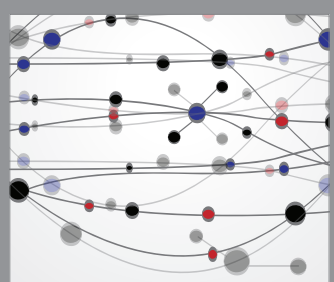

The Scientific World Journal
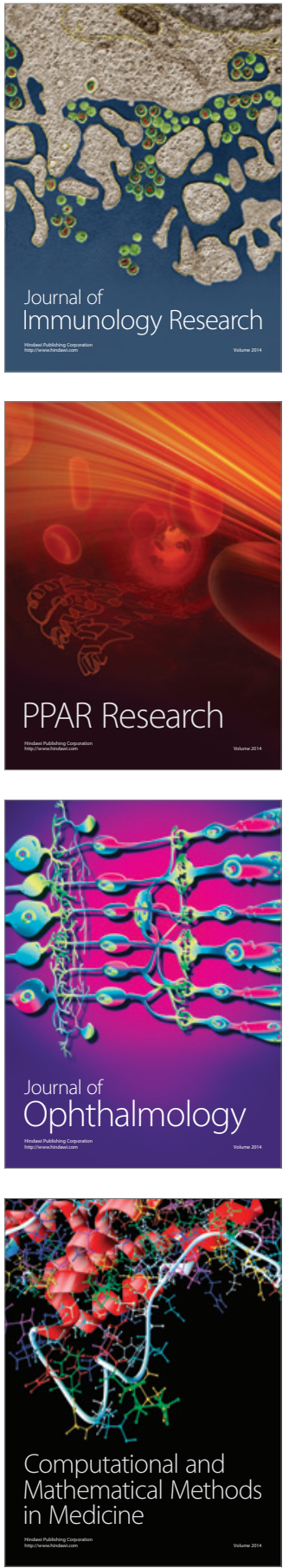

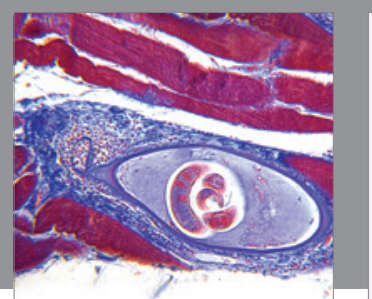

Gastroenterology Research and Practice

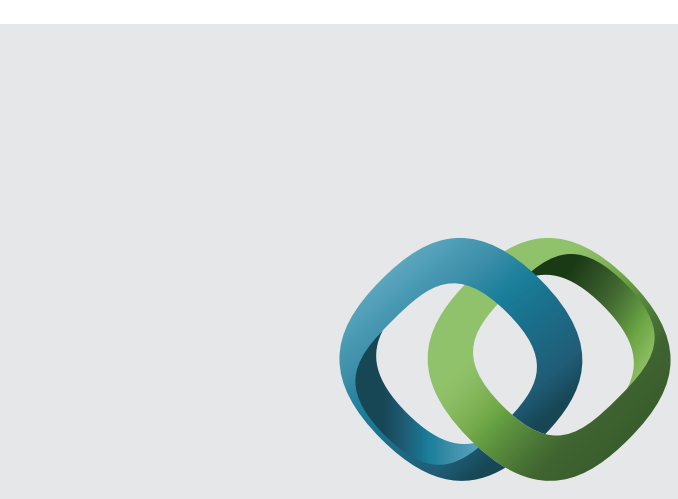

\section{Hindawi}

Submit your manuscripts at

http://www.hindawi.com
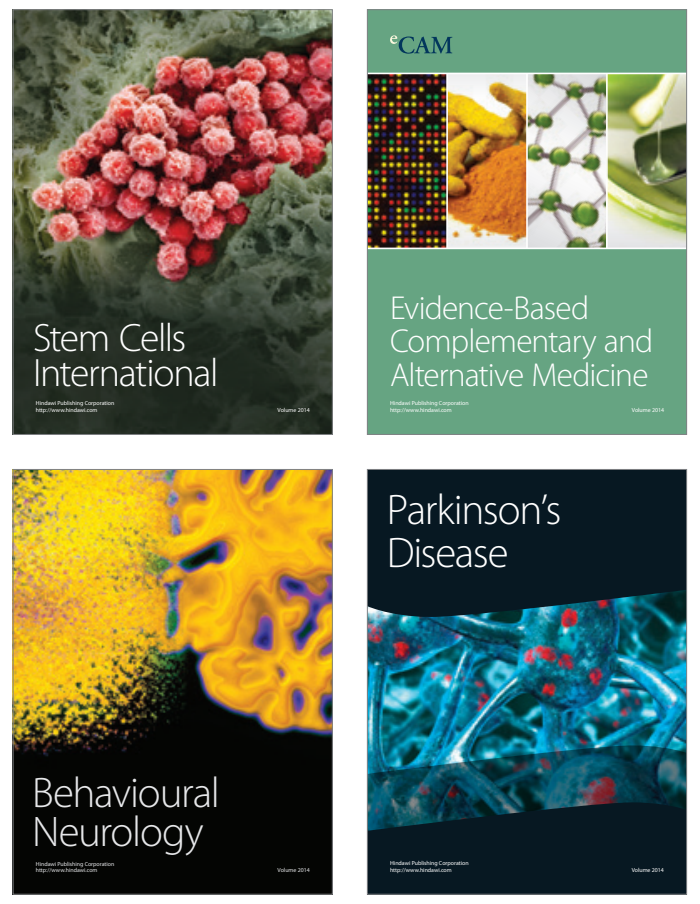
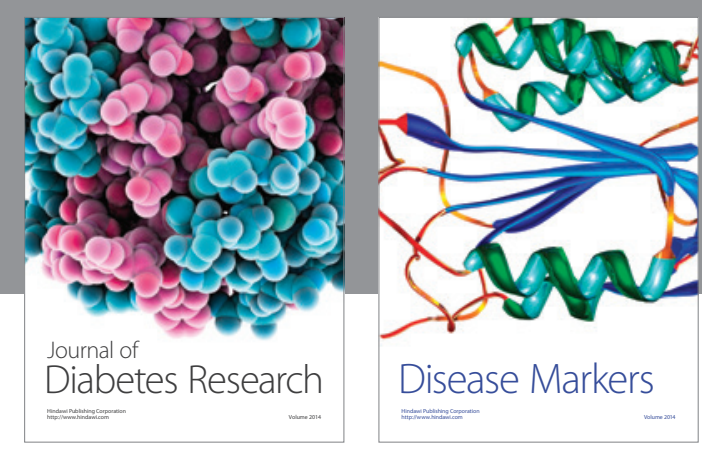

Disease Markers
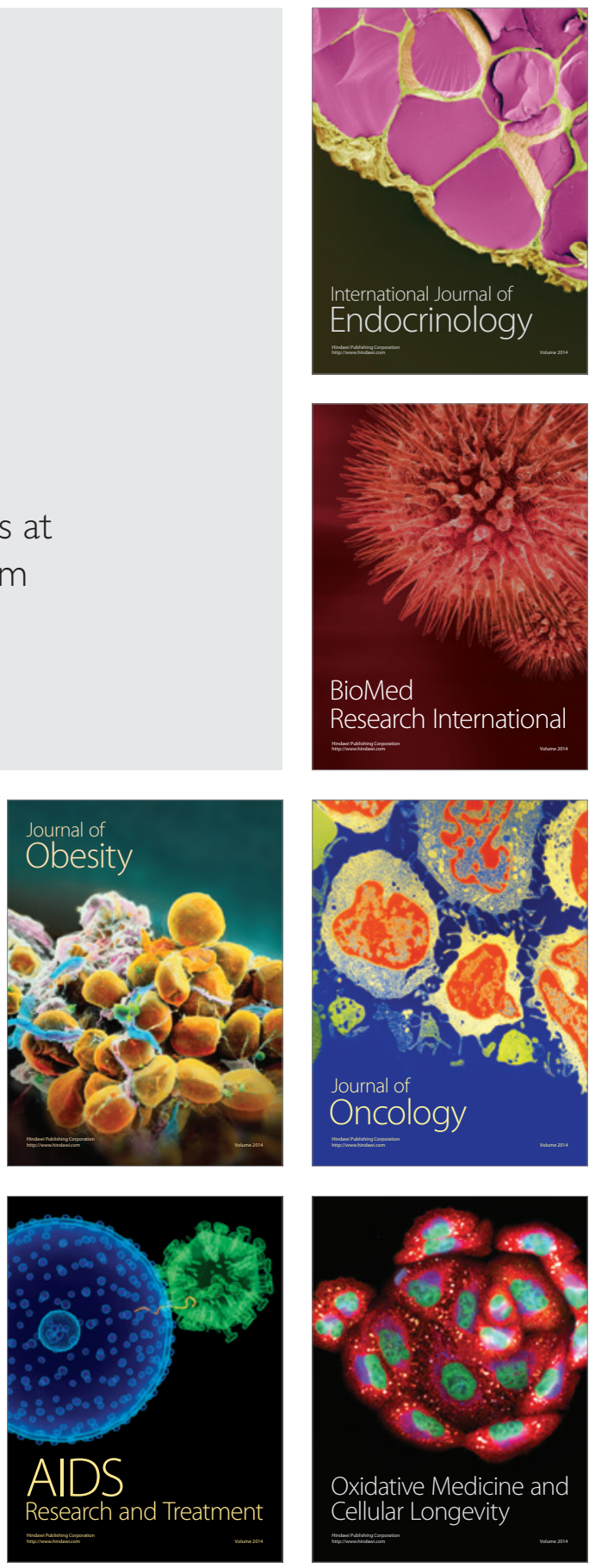